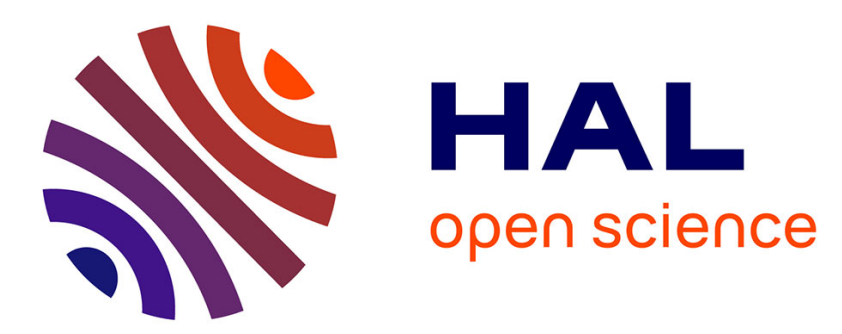

\title{
Oro-gastro-intestinal digestion of starch in white bread, wheat-based and gluten-free pasta: Unveiling the contribution of human salivary $\alpha$-amylase
}

Daniela Freitas, Steven Le Feunteun

\section{- To cite this version:}

Daniela Freitas, Steven Le Feunteun. Oro-gastro-intestinal digestion of starch in white bread, wheatbased and gluten-free pasta: Unveiling the contribution of human salivary $\alpha$-amylase. Food Chemistry, 2019, 274, pp.566-573. 10.1016/j.foodchem.2018.09.025 . hal-02627826

\section{HAL Id: hal-02627826 \\ https://hal.inrae.fr/hal-02627826}

Submitted on 30 Sep 2021

HAL is a multi-disciplinary open access archive for the deposit and dissemination of scientific research documents, whether they are published or not. The documents may come from teaching and research institutions in France or abroad, or from public or private research centers.
L'archive ouverte pluridisciplinaire HAL, est destinée au dépôt et à la diffusion de documents scientifiques de niveau recherche, publiés ou non, émanant des établissements d'enseignement et de recherche français ou étrangers, des laboratoires publics ou privés. 


\title{
Oro-gastro-intestinal digestion of starch in white bread, wheat-based and gluten-free pasta: unveiling the contribution of human salivary $\alpha$-amylase
}

\author{
Daniela Freitas ${ }^{1}$ and Steven Le Feunteun ${ }^{1}$ \\ ${ }^{1}$ UMR GMPA, AgroParisTech, INRA, Université Paris-Saclay, 78850, Thiverval- Grignon, France \\ * Corresponding author: steven.le-feunteun@inra.fr
}

\begin{abstract}
Starch is a major determinant of the glycemic responses elicited by our diets, but the exact contribution of the two main amylolytic enzymes (salivary and pancreatic $\alpha$-amylases) remains a matter of debate. Our aim was to investigate the contribution of the oral, gastric and intestinal phases to the hydrolysis of starch in bread and pasta during dynamic in vitro digestions using $\mathrm{DiDGI}^{\circledR}$. Before its inactivation by the low gastric $\mathrm{pH}$, salivary $\alpha$-amylase released about $80 \%$ of the starch in bread and $30 \%$ of that in pasta, hydrolysing over half of it into oligosaccharides. Accordingly, the contribution of pancreatic $\alpha$-amylase during the intestinal phase was lower for bread than pasta. Our results are well correlated with in vivo data, and demonstrate the importance of salivary $\alpha$-amylase during oro-gastric processing of starchy foods. This finding is discussed in relation with observations regarding salivary $\alpha$-amylase from other fields of knowledge.
\end{abstract}

Keywords: Amylolysis; Hydrolysis; Bread; Spaghetti; Carbohydrates; Saliva; Bolus

\footnotetext{
Abbreviations: HSA, Human salivary $\alpha$-amylase; GF, Gluten-free; GI, Glycemic Index; eSGF, Simulated Gastric Fluid electrolyte solution; eSIF, Simulated Intestinal Fluid electrolyte solution.
} 


\section{Introduction}

Starch is the most important, abundant and digestible polysaccharide in human nutrition. Being exclusively made up of glucose residues, and accounting for $20 \%$ to $50 \%$ of the total energy intake (Stylianopoulos, 2012), it plays a major role in the post-prandial glycemic responses elicited by our diets. The positive relationship between the rate at which foods are digested and the degree to which they raise blood glucose has been repeatedly acknowledged (Goñi, Garcia-Alonso, \& Saura-Calixto, 1997; Granfeldt, Hagander, \& Björck, 1995; Jenkins, et al., 1982). It is therefore clear that attention should not only be given to the starch content in our diets, but also to its digestive process, which remains to be fully understood. There are two key enzymes that participate in the digestion of starch: human salivary $\alpha$-amylase (HSA) and pancreatic $\alpha$-amylase. HSA initiates the amylolytic process in the oral cavity (Bornhorst \& Singh, 2012) and can remain active in the stomach (Bornhorst \& Singh, 2012; Gropper \& Smith, 2013) until it is inactivated due to the increasing acidity, between pH 3.0 and 3.8 (Freitas, Le Feunteun, Panouillé, \& Souchon, 2018; Fried, Abramson, \& Meyer, 1987). Pancreatic $\alpha$-amylase and brush border enzymes then complete starch digestion in the small intestine, where glucose is finally absorbed (Gropper \& Smith, 2013). The role of HSA during oral digestion of starch is somewhat well established, but little attention is given to its impact during the gastric phase of digestion. Extensive work has been conducted in vitro with the aim of better understanding the digestive process of starch (Berti, Riso, Monti, \& Porrini, 2004; Goñi, Garcia-Alonso, \& Saura-Calixto, 1997; Granfeldt, Hagander, \& Björck, 1995; Jenkins, et al., 1982; Woolnough, Bird, Monro, \& Brennan, 2010), but the oral phase is either ignored (Berti, Riso, Monti, \& Porrini, 2004; Goñi, GarciaAlonso, \& Saura-Calixto, 1997) or followed by a gastric phase at an acidic $\mathrm{pH}$, usually between 1.5 and 3 (Granfeldt, Hagander, \& Björck, 1995; Jenkins, et al., 1982; Minekus, et al., 2014; Woolnough, Bird, Monro, \& Brennan, 2010). Consequently, even when taken into account in these protocols, HSA is immediately inactivated at the beginning of the gastric phase, and therefore most starch is hydrolysed during the intestinal phase. Moreover, because such studies are generally in very good agreement with in vivo data 
(Bohn, et al., 2017) an analogy between intestinal hydrolysis kinetics and glycemic response is repeatedly established, thereby reinforcing the idea that the great majority of starch is digested by pancreatic amylase (des Gachons \& Breslin, 2016).

However, simulating gastric digestion at a stable acidic $\mathrm{pH}$ is not representative of the in vivo dynamics, as it has been observed that it takes 75-107 min to reach $\mathrm{pH} \leq 2$ after a meal (Dressman, et al., 1990; Gardner, Ciociola, \& Robinson, 2002; Malagelada, Go, \& Summerskill, 1979). This is in line with the reports that the action of HSA can continue long after the oral phase, and even reach the intestinal lumen in its active form (Fried, Abramson, \& Meyer, 1987; Skude \& Ihse, 1976). These observations suggest that HSA may play a more significant role in starch digestion than often considered. The scientific literature on this topic is scarce, but evidences that HSA can hydrolyse as much as $76 \%$ of mashed potatoes' starch and $59 \%$ of that in bread into maltose, within the stomach, date back to the beginning of the $20^{\text {th }}$ century (Bergeim, 1926). More recently, we obtained similar results with an in vitro protocol that closely mimicked in vivo gastric $\mathrm{pH}$ reduction kinetics after a snack- or lunch-type meal and showed that HSA could hydrolyse up to $80 \%$ of bread starch within the first 30 min of gastric digestion (Freitas, Le Feunteun, Panouillé, \& Souchon, 2018). In the present study, we intended to confirm that the amylolytic activity of saliva plays a preponderant role in the digestion of starch in bread and to widen our investigations to the intestinal phase of digestion, to the kinetics of starch hydrolysis into oligosaccharides, and to other highly consumed starchy foods: wheat and gluten free (GF) spaghetti. Our hypothesis is that HSA can significantly contribute to the digestion of starch before it is inactivated during the gastric phase, and therefore plays a more important role than generally considered.

\section{Materials and Methods}

\subsection{Materials}


The three test foods were purchased from a supermarket: freshly baked white wheat French baguette (common baguette, Auchan, Plaisir, France), no. 5 wheat spaghetti (Barilla Alimentari, Parma, Italy), and no. 5 gluten-free (GF) spaghetti (Barilla Alimentari, Parma, Italy) in which the wheat flour was replaced by a mixture of $95 \%$ maize and $5 \%$ rice flours. Whole saliva pool from 10 human donors (Normal saliva in 5 mL aliquots, ref. 991-05-P-5) was acquired from Lee Biosolutions (Maryland Heights, United States) and conserved at $-80^{\circ} \mathrm{C}$. Pepsin from gastric mucosa (P-6887), pancreatin (P-1750) and pancreatic $\alpha$-amylase (A-3176), all of porcine origin, were purchased from Sigma-Aldrich (Saint-Quentin Fallavier, France). Amyloglucosidase from Aspergillus Niger (ref. 10102857 001) was obtained from Roche (Rotkreuz, Switzerland) and was always used undiluted. The amyloglucosidase activity provided by the manufacturer (14 U/mg of protein) was used as reference, whereas the activities of saliva (345 $\pm 37 \mathrm{U} / \mathrm{mL}$ ), pepsin (3319 $\pm 70 \mathrm{U} / \mathrm{mg}$ ) and pancreatin (Trypsic activity of $3.42 \pm 0.04 \mathrm{U} / \mathrm{mg}$ ) were all measured in our lab according to previously described methods (Minekus, et al., 2014). D-Glucose kits (ref. 103.21) from BioSenTec (Auzeville Tolosane, France) were also used.

\subsection{Food preparation and characterization}

\subsubsection{Food preparation}

Only the crumb of the bread, separated from the crust using a 3-cm diameter cookie cutter cylinder, was used for the experiments. Both types of pasta were prepared in a Thermomix food processor (Thermomix TM 31, Vorwek, Nantes, France) following the same procedure: pasta was cooked in pre-heated salted (7 $\mathrm{g} / \mathrm{L}$ of $\mathrm{NaCl}$ ) mineral water (Evian, Évian-les-bains, France) for $11 \mathrm{~min}$ at $90{ }^{\circ} \mathrm{C}$ under the lowest speed (spoon function). Immediately after, the cooking water was drained and the pasta rinsed 3 times with mineral water. The ratio of pasta to water was kept at $17 / 100(w / w)$ both during cooking and rinsing.

\subsubsection{Water content}


The water content of food samples $(5 \mathrm{~g} \pm 0.5 \mathrm{~g}$ ) was determined in triplicate by measuring the weight loss after drying at 110 ㄷ for 24 hours in an oven (UF160, Memmert, Büchenbach, Germany).

\subsubsection{Starch}

Total and resistant starch contents were determined in triplicate and used to estimate digestible starch.

Total starch was quantified using a modified version of a previously described method (Goñi, GarciaAlonso, \& Saura-Calixto, 1997). Food samples (50 $\pm 5 \mathrm{mg}$ of bread crumb or cooked pasta) were dispersed in $10 \mathrm{~mL}$ of a $2 \mathrm{M} \mathrm{KOH}$ solution at $4^{\circ} \mathrm{C}$ for $16 \mathrm{~h}$ to allow for complete solubilisation. $5.7 \mathrm{~mL}$ of $2 \mathrm{M} \mathrm{HCl}$ and $3 \mathrm{~mL}$ of $0.4 \mathrm{M}$ sodium acetate buffer were then added and the $\mathrm{pH}$ was adjusted to $4.75 \pm 0.1$. Their solubilised starch was subsequently hydrolysed into glucose by adding $60 \mu \mathrm{L}$ of amyloglucosidase and incubating for $45 \mathrm{~min}$ in a shaking water-bath (SW22, Julabo, Seelbach, Germany) $\left(60^{\circ} \mathrm{C}, 150 \mathrm{rpm}\right)$. After centrifugation (Centrifuge $5804 \mathrm{R}$, Eppendorf, Hamburg, Germany) ( $4{ }^{\circ} \mathrm{C}, 3000 \mathrm{~g}, 10 \mathrm{~min}$ ), glucose concentration in the supernatant was determined using a D-Glucose kit followed by absorbance measurements $(340 \mathrm{~nm}$ ) in $1 \mathrm{~cm}$ plastic cuvettes using a UV-Vis spectrometer (Evolution 201, Thermo Fisher Scientific, Massachusetts, United States). The total starch content was calculated as mg of glucose $\times 0.9$.

Resistant starch was determined using a modified version of Goñi's method (Goñi, Garcia-Diz, Mañas, \& Saura-Calixto, 1996). Bread crumb (250 $\pm 5 \mathrm{mg}$ ) and cooked pasta (350 $\pm 5 \mathrm{mg}$ ) samples were incubated with $10 \mathrm{~mL}$ of $\mathrm{HCl}-\mathrm{KCl}$ buffer $(\mathrm{pH} 1.5)$ and $0.4 \mathrm{~mL}$ of a $1.25 \times 10^{5} \mathrm{U} / \mathrm{mL}$ pepsin solution in a shaking water bath $\left(40{ }^{\circ} \mathrm{C}, 150 \mathrm{rpm}, 60 \mathrm{~min}\right)$. Then, $9.5 \mathrm{~mL}$ of tris-maleate buffer $(\mathrm{pH}$ 6.9) and $1 \mathrm{~mL}$ of a $0.52 \mathrm{U} / \mathrm{mL}$ pancreatic $\alpha$-amylase solution were added and samples were incubated for $16 \mathrm{~h}$ at $37^{\circ} \mathrm{C}$ under agitation (150 rpm). After centrifugation $\left(4{ }^{\circ} \mathrm{C}, 3000 \mathrm{~g}, 15 \mathrm{~min}\right.$ ) and supernatant removal, the pellet was washed with $10 \mathrm{~mL}$ of distilled water and re-suspended in $6 \mathrm{~mL}$ of $2 \mathrm{M} \mathrm{KOH}$ where they were left for 30 min under constant shaking $(150 \mathrm{rpm})$ at $20^{\circ} \mathrm{C} .5 .5 \mathrm{~mL}$ of $2 \mathrm{M} \mathrm{HCl}$ and $3 \mathrm{~mL}$ of $0.4 \mathrm{M}$ sodium buffer acetate $(\mathrm{pH} 4.75)$ 
were added. These samples were then incubated with amyloglucosidase, centrifuged and the starch content of the pellet suspension (i.e. resistant starch) was quantified as glucose using the same conditions as previously provided for the total starch determination.

Digestible starch was calculated as the difference between total and resistant starch.

\subsubsection{Protein}

The protein content of the spaghetti was determined by the Kjeldahl method in an independent laboratory (ABIOPOLE - Groupe Qualtech, Vandœuvre, France) with a conversion factor of 5.7 between nitrogen and protein contents. The protein content of bread was estimated from the French Table of Food Composition corrected for the nitrogen conversion factor (5.7 instead of 6.25) and adjustment for the measured starch content (French Agency for Food Environmental and Occupational Health \& Safety, 2017).

\subsection{Dynamic in vitro digestion}

Dynamic in vitro digestions were conducted in triplicate for each food. Each digestion comprised an oral phase followed by gastrointestinal digestion in DiDGI ${ }^{\circledR}$ (INRA, Grignon, France), a computer controlled dynamic system (Ménard, et al., 2014). The STORM ${ }^{\circledR}$ (INRA, Grignon, France) software was used to continuously monitor digestive conditions and control the fluxes of secretions according to pre-set parameters. The composition of the simulated secretions used during the gastric and intestinal phases of digestion are described below and were defined in order to remain close to the recommendations provided in the standardized static in vitro digestion method (Minekus, et al., 2014). Whenever possible, data from human studies were used as reference to define the experimental conditions.

\subsubsection{Oral phase}

For practical reasons, food comminution and saliva incorporation were dissociated. 
Comminution: Different procedures were followed for bread and pasta. Bread crumb was fragmented using a domestic kitchen food chopper (Multi-moulinette $400 \mathrm{~W}$, Moulinex, Ecully, France) using 4 segments of $5 \mathrm{~s}$ separated by intervals of $5 \mathrm{~s}$. We have previously shown that this enables to accurately replicate the starch digestion kinetics obtained using bread boli formed in vivo (Freitas, Le Feunteun, Panouillé, \& Souchon, 2018). This procedure was unsuitable for pasta. As most masticated spaghetti pieces have been reported to be between 5 to $30 \mathrm{~mm}$ long (Hoebler, Devaux, Karinthi, Belleville, \& Barry, 2000), pasta was comminuted by manually chopping spaghetti strands into $10 \mathrm{~mm}$ long pieces with a knife. Individual portions of comminuted bread $(6.4 \pm 0.5 \mathrm{~g})$ and wheat $(11.0 \pm 0.5 \mathrm{~g})$ and GF $(10.8 \pm 0.5 \mathrm{~g})$ pasta, equivalent to $3 \mathrm{~g}$ of total starch, were kept in an air-tight container at $20{ }^{\circ} \mathrm{C}$ until saliva incorporation (maximum of 1 hour).

Saliva incorporation: Saliva was heated to $37^{\circ} \mathrm{C}$ in a water-bath for $10 \mathrm{~min}$ immediately before each digestion experiment. One portion of comminuted food was mixed with saliva for $30 \mathrm{~s}$ using a spatula at a saliva/food mass ratio of 0.2 and 0.05 for bread and pasta, respectively. Saliva incorporation levels and mixing times were based on the results of Human studies with the same types of foods (Hoebler, Devaux, Karinthi, Belleville, \& Barry, 2000; Jourdren, et al., 2016).

\subsubsection{Gastric phase}

The gastric compartment of DiDGI ${ }^{\circledR}$ was prepared with an operating temperature of $37^{\circ} \mathrm{C}$ and a stirring speed of $10 \mathrm{rpm}$. The fasted gastric content consisted of $20 \mathrm{~mL}$ of a Simulated Gastric Fluid electrolyte solution (eSGF), $10 \mu \mathrm{L}$ of $0.3 \mathrm{M} \mathrm{CaCl}_{2}$, and a predetermined volume of water. The composition of all electrolyte solutions was based on the literature (Minekus, et al., 2014), the only difference being that eSGF was prepared at a neutral $\mathrm{pH}$ so that the kinetics of gastric $\mathrm{pH}$ reduction in vivo could be mimicked. To standardize digestive conditions of all foods and ensure adequate immersion of the pH probe, the water volume was adjusted according to the bolus volume so that the initial volume of the gastric contents was 
always $40 \mathrm{~mL}$ after the bolus addition. Each bolus was introduced into the gastric compartment immediately after preparation where it was mixed with the gastric contents for $30 \mathrm{~s}$. At this point, stirring was interrupted for another $30 \mathrm{~s}$ to allow for particle sedimentation before collecting the first sample ( 2 $\mathrm{mL}$ ) from the supernatant. Stirring was then resumed and the gastric phase was initiated by activating the influx of $\mathrm{HCl}(0.1 \mathrm{M}$ in eSGF) and pepsin (4700 U/mL in eSGF). Practical constraints, imposed by the sample collection and gastric phase preparation procedures, resulted in a 2 min lag between the end of the oral phase and the start of gastric digestion. This was the shortest time possible to complete all the experimental steps. The influx of $\mathrm{HCl}$ was automatically controlled by $\mathrm{STORM}^{\circledR}$ to reduce the $\mathrm{pH}$ from 6 (initial pH of chime 5.9) to 2 in $90 \mathrm{~min}$ and keep it at 2 for the following $30 \mathrm{~min}$. This was intended to replicate the $\mathrm{pH}$ evolution observed during the digestion of main meals (comparable to a lunch or dinner) (Dressman, et al., 1990; Gardner, Ciociola, \& Robinson, 2002; Malagelada, Go, \& Summerskill, 1979). The flow rate of the pepsin solution $(4705 \mathrm{U} / \mathrm{mL})$, also controlled by $\mathrm{STORM}^{\circledast}$, was constant and pre-set to achieve a concentration of $\approx 2000 \mathrm{U} / \mathrm{mL}$ within $90 \mathrm{~min}$. The total volume of the $\mathrm{HCl}$ and pepsin solutions added during the gastric phase was $22 \pm 2 \mathrm{~mL}$. This was defined after preliminary tests in order to compensate the volume withdrawn by sampling. A total of 11 more samples were indeed collected from the supernatant at $3,6,9,15,20,30,45,60,75,90$ and 120 min using the above-described procedure (interruption of stirring for $30 \mathrm{~s}$ immediately before collecting a $2 \mathrm{~mL}$ sample). Collected samples were immediately placed in a dry bath (ThermoMixer C, Eppendorf, Hamburg, Germany) $\left(99^{\circ} \mathrm{C}, 150 \mathrm{rpm}, 5 \mathrm{~min}\right.$ ) for enzyme inactivation, cooled down on ice, and conserved at $-20^{\circ} \mathrm{C}$ until further analysis.

\subsubsection{Intestinal phase}

Intestinal digestion was conducted in the same DiDGI ${ }^{\circledR}$ compartment. $22 \mathrm{~mL}$ of a Simulated Intestinal Fluid electrolyte solution (eSIF), $10 \mathrm{~mL}$ of water and $80 \mu \mathrm{L}$ of $0.3 \mathrm{M} \mathrm{CaCl}_{2}$ were added to the chime remaining after the gastric phase $(38 \pm 2 \mathrm{~mL}$ ). The $\mathrm{pH}$ of the mixture was adjusted to 7.0 with $1 \mathrm{M} \mathrm{NaOH}$ and the 
intestinal phase was initiated by adding $10 \mathrm{~mL}$ of a pancreatin solution in eSIF (trypsic activity of $800 \mathrm{U} / \mathrm{mL}$ ) that ensured a trypsin activity of $103 \mathrm{U} / \mathrm{mL} \pm 3 \mathrm{U} / \mathrm{mL}$ and a total volume close to $80 \mathrm{~mL}$ at the start of the intestinal phase. STORM ${ }^{\circledR}$ was programmed to automatically maintain the $\mathrm{pH}$ at 7.0 by adding $0.02 \mathrm{M}$ $\mathrm{NaOH}$ (also prepared in eSIF). Supernatant samples were collected at 4, 9, 15, 20, 30, 60, 90 and 120 min employing the same procedure described in section 2.3.2.

\subsection{Digestion monitoring and chemical analyses}

All digestion experiments were monitored qualitatively (visual analysis of the devolution of food macrostructure) and quantitatively (dry mass and proportions of starch released and hydrolysed into oligosaccharides). Before analysis, samples were thawed at $4{ }^{\circ} \mathrm{C}$ and centrifuged $\left(10 \mathrm{~min}, 3000 \mathrm{~g}\right.$ and $\left.4{ }^{\circ} \mathrm{C}\right)$ to separate the suspended fine particulate fragments released during food disintegration from the liquid medium containing starch hydrolysis products, including oligosaccharides. Both the fine particle pellets and supernatants were recovered and kept at $-20{ }^{\circ} \mathrm{C}$ until further analysis. All the analyses of the centrifuged fractions were performed after thawing $\left(4^{\circ} \mathrm{C}\right)$.

\subsubsection{Devolution of food macrostructure and fine particle pellets dry masses}

The devolution of food macrostructure was followed through camera pictures taken at the end of the oral phase, and after $60 \mathrm{~min}$ and $120 \mathrm{~min}$ of both the gastric and intestinal phases of digestion (i.e. $\mathrm{t}=0,60$, 120,180 and 240 min of gastro-intestinal digestion). Additionally, the dry masses of the fine particle pellets (18h at $110^{\circ} \mathrm{C}$ in an oven) were used as a quantitative indicator of food degradation throughout digestion and to correct for losses of undigested/unreleased starch during sampling assuming that the fraction of starch in the fine particle pellet was inversely proportional to the fraction of released starch (section 2.4.2). Undigested starch in the fine particle pellets was estimated as follows:

$$
\text { Undigested starch lost }(g)=\frac{T S d r y \text { food }}{100} \times \text { dry pellet } \times \frac{\text { S pellet }}{100}
$$


where TS dry food is the proportion (\%) of total starch in the dry food sample, dry pellet is the dry mass of fine particle pellet $(\mathrm{g})$ obtained after centrifugation of the digestion sample, and $S$ pellet is the proportion of starch in the fine particle pellet (\%), estimated as $100-\%$ of total starch released (determined after analysis of the corresponding supernatant fraction as described in section 2.4.2.).

\subsubsection{Starch release from the food matrix}

Released starch refers to all solubilised starch fractions and products of starch hydrolysis. This starch fraction was measured as glucose after incubation with amyloglucosidase and centrifugation, as previously described (section 2.2.3). Released starch was expressed as the percentage of total starch released over time, after correction for starch losses during sampling (section 2.4.1).

\subsubsection{Oligosaccharides release}

The proportion of starch hydrolysed into oligosaccharides, with degrees of polymerization of up to 10 (Hoebler, et al., 1998), was estimated as follows. $50 \mu \mathrm{L}$ of supernatant were added to $400 \mu \mathrm{L}$ of $80 \%(\mathrm{v} / \mathrm{v})$ ethanol and an overnight incubation followed (16 h, $4{ }^{\circ} \mathrm{C}$ ) (Ballance, et al., 2013; Hoebler, et al., 1998; Mishra, Hardacre, \& Monro, 2012). After centrifugation $\left(10 \mathrm{~min}, 1000 \mathrm{~g}, 4^{\circ} \mathrm{C}\right)$, the oligosaccharide fraction, recovered in the supernatants was quantified as glucose after incubation with amyloglucosidase and centrifugation, as previously described (section 2.2.3). The oligosaccharide content of the samples was calculated as $\mathrm{mg}$ of glucose $\times$ 0.9. The oligosaccharide release was expressed as the percentage of total starch over time, after correction for starch losses during sampling (section 2.4.1).

\subsection{In vitro prediction of the Glycemic Index}

The glycemic index (GI) of each food was estimated using the in vitro procedure described by (Goñi, GarciaAlonso, \& Saura-Calixto, 1997). Briefly, $50 \mathrm{mg}$ of food samples were incubated $\left(1 \mathrm{~h}, \mathrm{pH} 1.5,37^{\circ} \mathrm{C}\right)$ with pepsin $(5531 \mathrm{U} / \mathrm{mL}$ in the final mixture) to simulate gastric proteolysis, their $\mathrm{pH}$ was then adjusted to 6.9 
and they were incubated at $37^{\circ} \mathrm{C}$ for $180 \mathrm{~min}$ with pancreatic $\alpha$-amylase $(0.43 \mathrm{IU} / \mathrm{mL}$ in the final mixture) to simulate intestinal amylolysis. During this second incubation, $1 \mathrm{~mL}$ samples were collected from the supernatant every $30 \mathrm{~min}$ and immediately transferred to a boiling water bath to inactivate $\alpha$-amylase $\left(100{ }^{\circ} \mathrm{C}, 5 \mathrm{~min}\right)$. All samples were stored at $4{ }^{\circ} \mathrm{C}$ for $24 \mathrm{~h}$ before being analysed using the procedure described in section 2.2.3 for solutions of solubilised starch. Partially hydrolysed starch was calculated as $\mathrm{mg}$ of glucose $\times 0.9$. The rate of starch digestion was expressed as the percentage of total starch released as a function of time and the predicted $\mathrm{Gl}$ was calculated based on the $\%$ of starch released at $90 \mathrm{~min}\left(\mathrm{H}_{90}\right)$ using the equation $\mathrm{GI}=39.21+0.803\left(\mathrm{H}_{90}\right)$. Each food was analysed in triplicate.

\section{Results}

\subsection{Food characterization}

The water, starch and protein contents of each food is presented in Table 1. Globally, bread contained less water (45.7 \%) than wheat and gluten-free pasta (65-69\%), but had a higher starch content (47.2 vs. 27$28 \%$ ). The proportions of resistant starch in bread and GF pasta were similar (between $3.4 \%$ and $4.2 \%$ of total starch) and about three times lower than in wheat pasta (13.4\%). The protein content of wheat spaghetti $(\approx 5 \%$, w/w) was about twice that of GF spaghetti.

\subsection{Dynamic in vitro digestion}

Dynamic digestions of bread, wheat and GF spaghetti comprising oral (2.5 min), gastric and intestinal phases (120 min each) were carried out in triplicate. Both qualitative and quantitative methods were employed to monitor (1) the devolution of food macrostructure, (2) the starch release from the food matrix, and (3) its hydrolysis into oligosaccharides.

\subsubsection{Devolution of food macrostructure}


The visual appearance of the chimes during the digestion experiments is presented in Figure 1 . The digestion of bread was characterized by a somewhat homogeneous chime. Individual particles could hardly be distinguished in the beginning and were completely dissolved by the end of the gastric phase. In contrast, particles of both types of pasta were clearly identifiable until the end of gastric digestion even though their degradation evolved differently. Despite equivalent initial particle size and shape, wheat pasta tended to be degraded faster during gastric digestion. During the first $60 \mathrm{~min}$, wheat pasta particles were broken down into numerous, visibly smaller, pieces, with only a few remaining at 120 min. Particles of GF pasta seemed more resistant with many particles having retained their shape and size after $60 \mathrm{~min}$, and some relatively large pieces were still visible at $120 \mathrm{~min}$. During the intestinal phase, the opposite trend was observed. The remaining particles of GF pasta were rapidly disintegrated leading to a macroscopically homogenous solution, comparable to the bread chime, whereas the particles of wheat pasta appeared to be more resistant to intestinal digestion, with a number of them still visible at the end of the experiments.

\subsubsection{Dry mass of the fine particulate fraction}

The dry masses of the fine particulate material recovered in the $3000 \mathrm{~g}$ pellets from the liquid phase of the digestion, presented as percentages of the total dry mass of the corresponding food at the start of digestion, are presented in Figure 2 (white circles) and can be used as a complementary indicator of the rate of food degradation. For bread, there was a steep rise during the very first minutes of digestion up to $\approx 1.4 \%$, followed by a reduction between 30 and $60 \mathrm{~min}$ that stabilised at about $0.7 \%$ resulting in a plateau that lasted until the end of the gastric phase. The data for wheat and GF pasta showed a more steady increase during the first 60 min up to a plateau that lasted until the end of gastric digestion. The plateau reached with wheat pasta was close to the first one observed for bread, at about $1.5 \%$, whereas it was 
lower than $1 \%$ for GF pasta. The results obtained during the intestinal digestions were similar for both types of pasta and close to those obtained for bread, with stable plateau values in the range of $0.3-0.7 \%$.

The cumulative fine particle pellet mass is also represented in Figure 2 (dashed line) for two main purposes. First, it clearly illustrates the overall tendency that can be drawn from these measures: the rate of bolus disintegration into small pieces (small enough to be sampled out but large enough to be recovered in the fine particle pellet upon centrifugation) during gastric digestion seemed to increase in the following order: GF pasta < wheat pasta < bread, a finding that correlates well with the previously described visual observations (Figure 1). Second, it shows that a significant amount of food was sampled out during the course of the experiments (from 10 to $16 \%$ ) and represented loss of substrate that needed to be taken into account in the calculations of released starch and oligosaccharides.

\subsubsection{Starch release and hydrolysis into oligosaccharides}

Figure 3 shows the kinetics of starch release and hydrolysis into oligosaccharides during digestion of bread (A), wheat pasta (B) and GF pasta (C). Released starch refers to the proportion of starch that was released from the food matrix into the chime and recovered in the sample supernatants regardless of its level of degradation. In contrast, released oligosaccharides reflect an extensive hydrolysis of starch, constituting a good indicator of the extent of the amylolytic process. The first point in each graph $(\mathrm{t}=0 \mathrm{~min})$ corresponds, simultaneously, to the end of the oral phase $(2.5 \mathrm{~min})$ and the beginning of gastric digestion, and the point at 120 min marks the transition to the intestinal phase. Starch release and its hydrolysis into oligosaccharides were initiated during the oral phase. During the gastric phase both phenomena exhibited "rise-plateau" profiles, with a 30-45 min long initial increase followed by a plateau that lasted until the start of the intestinal phase $(t=120 \mathrm{~min})$. Immediately after the addition of pancreatin, the release of starch and oligosaccharides showed a second rise before new plateaus were reached. While these "riseplateau" digestion profiles during gastric and intestinal processing were common to all foods, the 
contribution of each digestive phase differed: bread starch was mainly released and hydrolysed during the gastric phase (Figure $3 \mathrm{~A}$ ), whereas most of that in pasta was digested during the intestinal phase (Figure $3 B$ and C).

According to the starch release curves (dark squares), oral digestion caused the release of $24 \%$ of bread starch, a value that increased to $80 \%$ within only 20 min of gastric digestion. Oral and gastric digestion of both pastas appeared slower and less extensive. Starch released during the oral phase amounted to around $3.5 \%$ of the total, and the plateau, reached later than for bread, corresponded to only $\approx 30 \%$ of the total starch. Consequently, intestinal digestion of bread starch was characterized by a very slight increase, of about $7 \%$ (final plateau at $87 \%$ ), whereas intestinal digestion of both pastas showed a fast and intense release of the remaining starch (measured at 94 and $100 \%$ of total starch in wheat and GF pasta, respectively, at the end of the experiment).

According to the results in Figure 3 (white squares), $16 \%$ of bread starch and almost all of the starch released from both pastas, was hydrolysed into oligosaccharides during the oral phase. During gastric digestion, more than half of the starch released from all foods was hydrolysed into oligosaccharides within 30-45 min. During intestinal digestion, starch hydrolysis into oligosaccharides was resumed and progressed rapidly for all foods, leading to plateaus corresponding to about $67-95 \%$ of the total starch.

\subsection{In vitro prediction of the Glycemic Index (GI)}

The starch release kinetics obtained using the in vitro protocol for GI prediction (Goñi, Garcia-Alonso, \& Saura-Calixto, 1997) are presented in Figure 4 (white symbols). According to these results, bread exhibited the highest hydrolysis rate with a plateau corresponding to approximately $83 \%$ of the total starch reached within $60 \mathrm{~min}$. Despite the different compositions of wheat and gluten-free pastas, no differences were observed between their starch digestion rates. In both cases, almost linear curves were obtained and starch was released slowly. More than $75 \%$ of the starch had not yet been released after $180 \mathrm{~min}$. The 
predicted Gls estimated from these data were $100 \pm 1.9,47.6 \pm 4.0$ and $47.4 \pm 1.6$, for bread, wheat and GF pastas, respectively.

The starch release kinetics during the gastric phase of our digestions, obtained using the same sample analytical procedures, are also plotted in Figure 4 (grey symbols) for comparison purposes. Although the enzymes and experimental conditions are not the same, the results were highly comparable, being possible to observe, in both cases, a much faster starch release for bread, and a similar (much lower) rate for both types of spaghetti.

\section{Discussion}

The role of Human salivary $\alpha$-amylase (HSA) in starch digestion is often overlooked in favour of that of pancreatic $\alpha$-amylase. Conducting in vitro digestions that mimic in vivo reality in terms of gastric $\mathrm{pH}$ and chronology of enzymatic action, we have recently shown that salivary amylase can, in fact, play a preponderant role in the gastric digestion of bread starch before being inactivated by acidity (Freitas, Le Feunteun, Panouillé, \& Souchon, 2018). In the present study, we intended to widen our investigations to complementary sample analyses and to other highly consumed starchy foods (spaghetti) throughout the course of semi-dynamic oro-gastro-intestinal in vitro digestions.

\subsection{General considerations}

We may first highlight the good agreement between the different methods used to monitor the digestion experiments. For example, bread particles were the smallest after the oral phase (Figure 1), rapidly becoming small enough to be sampled with $1 \mathrm{~mL}$ graduated pipettes (inner diameter of $1.5 \mathrm{~mm}$ ) during the gastric phase. This explains the faster increase of the fine particle pellet dry mass (Figure 2), and is also in agreement with the much higher starch release and hydrolysis rates observed for bread than for wheat 
and GF spaghetti during gastric digestion (Figure 3). The overall behaviour of both types of pasta was similar but a close inspection of the slight differences between them appears to show consistent trends among the different sets of results. Wheat pasta particle size was visibly reduced faster than that of GF pasta during gastric digestion, accordingly, the dry fine particle pellet mass for wheat pasta tended increase faster at this stage. The reverse tendency was then observed during the intestinal phase, only wheat pasta fragments were still visible at the end of the experiments what correlates well with the lower extents of starch release and hydrolysis observed for this food (Figure 3B).

\subsection{Gastric and intestinal contributions to starch digestion}

The shape of the starch and oligosaccharide release kinetics (Figure 3), with 2 successive increases for all foods, is explained by the chronology of enzymatic activity. The first rise corresponds to the action of HSA before it is completely inactivated by the increasing acidity of the chime. Indeed, we have previously shown that the amylolytic activity of saliva is completely lost bellow pH 3.5 , but is still close to $50 \%$ of its optimal activity at pH 4.0 (Freitas, Le Feunteun, Panouillé, \& Souchon, 2018). According to the gastric pH reduction kinetics used here, based on in vivo data following a full meal (Malagelada, Go, \& Summerskill, 1979), $\mathrm{pH} 4.0$ was reached at $45 \mathrm{~min}$, and $\mathrm{pH} 3.0$ at $67 \mathrm{~min}$. Therefore it seems that the released starch and oligosaccharides plateaued slightly before complete HSA inactivation, suggesting that the limiting factor could be the impaired accessibility of the remaining starch to HSA. Porcine pepsin, in turn, starts to be active below pH 4.0 (Kondjoyan, Daudin, \& Santé-Lhoutellier, 2015; Pletschke, Naudé, \& Oelofsen, 1995), when HSA is about to be totally inactivated. The hydrolysis of the protein network that entraps the remaining starch can therefore be considered to take place during the second hour of gastric digestion only. During this period, the amount of released starch tended to increase slightly for pasta (Figure 3B and

C) but our results indicate that pepsin action had limited consequences. The second rise, observed during the intestinal phase, can be attributed to the presence of pancreatic enzymes. Pancreatic $\alpha$-amylase 
further advances the amylolytic process and benefits from the preceding (pepsin) and concomitant (pancreatic proteases) hydrolysis of the protein network that improves the accessibility to starch. According to these considerations, the ratio between the two plateaus is therefore indicative of the gastric and intestinal contributions to the digestion of starch from each of the studied foods.

The fastest starch hydrolysis rate was observed for bread. We had recently shown that as much as $80 \%$ of bread starch can be released during the first 20 min of gastric digestion (Freitas, Le Feunteun, Panouillé, \& Souchon, 2018). Our current results therefore confirm that HSA can be responsible for an extensive amylolysis before the chyme is emptied into the small intestine. Moreover, they also show that starch hydrolysis was more important during the gastric phase, where $\approx 60 \%$ of starch was degraded into oligosaccharides, than during intestinal digestion (a further increase of $\approx 20 \%$ ). Between our current and previous investigations, conducted with different salivas, breads and $\mathrm{pH}$ reduction kinetics, we have covered a wide range of scenarios from what could be considered physiologically fast to slow gastric $\mathrm{pH}$ reduction kinetics (from pH 6 to 2 in 30 to $90 \mathrm{~min}$ ) and low to high levels of saliva incorporation in the bolus (from 0.2 to $0.5 \mathrm{~mL}$ per gram of bread crumb). We may therefore confidently state that the contribution of HSA to the digestion of bread starch is highly relevant in a wide range of conditions.

Wheat pasta elicited a lower starch digestion rate than wheat bread, in agreement with previous in vitro (Berti, Riso, Monti, \& Porrini, 2004) and in vivo (Packer, Dornhorst, \& Frost, 2000) studies. The contribution of HSA during the gastric digestion of wheat pasta, although not negligible, was considerably lower, representing a little more than a third of that for wheat bread. A first, and obvious, cause lies in the distinct saliva contents of the boluses that, with the intention of replicating those found in vivo (Hoebler, Devaux, Karinthi, Belleville, \& Barry, 2000; Jourdren, et al., 2016), were 4 times higher for bread than pasta. But the different saliva incorporation levels and amylolysis rates of each food can be related to their structural properties. At a macroscopic level, the porous structure of bread facilitates water infiltration (Mathieu, et 
al., 2016), and thus impregnation of saliva and secretions carrying digestive enzymes. In contrast, pasta is a densely packed product through which water penetration is limited, even during boiling (Cunin, Handschin, Walther, \& Escher, 1995). At a molecular level, the starch in bread crumb is found in a rather uniform gelatinization state, forming a continuous network that contains swollen starch granules and starch that leached out from the granules (Gray \& Bemiller, 2003). In turn, the level of starch gelatinization in cooked wheat spaghetti decreases progressively towards the centre of the spaghetti strand, and the density of the protein network is increasingly higher (Cunin, Handschin, Walther, \& Escher, 1995; Fardet, et al., 1998). Because granule swelling and dispersion of starch polysaccharides during gelatinization render starch increasingly more accessible to $\alpha$-amylase action (Mishra, Hardacre, \& Monro, 2012), starch in bread crumb is much more accessible than starch in pasta for which the vulnerability to hydrolysis gradually lowers towards the centre of spaghetti strands.

The rate of starch hydrolysis during gastric digestion of wheat spaghetti was similar to that of GF spaghetti, but it was slightly lower during the intestinal phase. In parallel, despite the same initial particle size and digestive conditions, particles of wheat pasta were degraded faster than those of GF pasta in the gastric phase, whereas the opposite was observed in the intestinal phase (Figure 1). The gluten network has been reported to slowdown enzymes' accessibility to starch (Fardet, et al., 1998). Therefore, one could have expected a constantly higher digestion rate from GF pasta, as previously observed in vitro (Jenkins, et al., 1987) and in vivo (Jenkins, et al., 1987; Johnston, Snyder, \& Smith, 2017). The recommended cooking times are slightly different for wheat (9 $\mathrm{min}$ ) and GF pasta (10 min). By cooking both foods at the same temperature for 11 minutes, it is possible that starch gelatinization in wheat pasta was slightly higher, further disrupting the surrounding gluten network. This might be the reason why we observed a faster degradation of wheat pasta during the gastric phase. However, wheat spaghetti had twice as much protein as GF spaghetti and, as mentioned above, it is also known that the density of the gluten network increases towards the interior of wheat spaghetti strands. As a consequence, wheat pasta could be expected to 
exhibit an increasing resistance to degradation, as we observed during the intestinal phase. There are, however, other relevant factors, such as product formulation and processing techniques, that can counterbalance the potential effects of wheat protein removal (Pellegrini \& Agostoni, 2015) to generate GF formulations that do not affect the glycemic response adversely, as it was previously found in vitro (Berti, Riso, Monti, \& Porrini, 2004) and in vivo (Packer, Dornhorst, \& Frost, 2000).

\subsection{In vivo data supporting our findings}

On the one hand, it is clear that the structural properties of food can strongly impact the rate of starch digestion and consequently the glycemic indexes. On the other hand, it is also evident that food structure can be extensively disrupted in the digestive stages that precede intestinal digestion, hence diminishing potential differences derived from the structural properties of each food. This is indeed what our results show: important differences in the extent of oro-gastric starch digestion for bread and pasta that nearly vanished within 30 min of intestinal digestion only. As it was shown above, these results are consistent with both in vitro digestibility assays to predict the glycemic response and in vivo data. One may therefore question the assumption that pancreatic amylase always plays the predominant role in the digestion of starchy foods driving the attention to HSA, which is the most susceptible of being influenced by food structure.

To the best of our knowledge, the main arguments serving as a justification for the limited extent of HSA's contribution to starch digestion are the short duration of the oral phase and the erroneous idea that this enzyme is quickly inactivated once food boluses are swollen. Although HSA has been extensively studied, its usefulness to digestion is still questioned (des Gachons \& Breslin, 2016; Fernández \& Wiley, 2017) even though strong hints that its role is more relevant than what is generally considered can be recurrently found. Oral food processing is indeed brief but, as we have discussed above, HSA can continue hydrolysing starch in the stomach for long periods of time. For instance it has been observed that after the 
consumption of a liquid meal, the $\mathrm{pH}$ was still above 5.0 at half-gastric emptying time (48 $\pm 28 \mathrm{~min}$.) and reached 3.0 only after more than $80 \%$ of the gastric contents were emptied (Carrière, Renou, Ville, Grandval, \& Laugier, 2001). This can explain Bergeim's findings, who found that more than half of the starch in mashed potatoes and bread was extensively digested in the stomach (Bergeim, 1926). Additionally, it has also been shown that swallowing high- (ex. potato or corn) but not low-starch (apple) foods without chewing resulted in the reduction of starch digestibility, and the associated glycemic response (Read, et al., 1986). This is also in line with a number of evolutionary concepts suggesting that increased HSA expression would have improved the efficiency of starch digestion, constituting a fitness advantage that drove a positive selection phenomenon in at least some high starch-populations (Perry, et al., 2007). Accordingly, a positive association between a high HSA activity and populations consuming a diet consisting predominantly on carbohydrates, has been repeatedly highlighted (des Gachons \& Breslin, 2016; Perry, et al., 2007; Squires, 1953). Our observations, together with the work of all these research teams, undeniably strengthen HSA's role in the digestive process and also imply that this enzyme's contribution to gastric digestion is highly likely to play a part in the definition of the glycemic response elicited by starchy foods.

\section{Conclusion}

The present study not only confirms the important role played by HSA during the gastric digestion of bread, but also demonstrates that, despite the more compact structure of pasta and a much lower level of saliva incorporation during bolus formation, the contribution of salivary amylase to the digestion of starch in pasta is far from being negligible. The starch digestion rates during gastric digestion were well correlated with a widely used in vitro protocol to estimate the GI of foods and with other in vivo studies. Given HSA's relevant role in starch digestion, it is highly likely that factors influencing its amylolytic performance, other 
than the structural properties of a food, may translate into an altered glycemic response. This could open new opportunities and strategies to attenuate the high glycemic response to some starchy foods by inhibiting HSA.

\section{Acknowledgments}

We would like to thank David Forest and Thomas Cattenoz for their technical help in the laboratory. We would like to acknowledge the IDEX-Paris Saclay consortium for partially supporting this research through a PhD grant and we are grateful to François Boué and Evelyne Lutton for their important help in obtaining this doctoral grant and helpful discussions.

\section{Conflict of interest}

The authors have no conflict of interest to declare.

\section{References}

Ballance, S., Sahlstrøm, S., Lea, P., Nagy, N. E., Andersen, P. V., Dessev, T., Hull, S., Vardakou, M., \& Faulks, R. (2013). Evaluation of gastric processing and duodenal digestion of starch in six cereal meals on the associated glycaemic response using an adult fasted dynamic gastric model. European Journal of Nutrition, 52(2), 799-812.

Bergeim, O. (1926). Intestinal chemistry: iii. Salivary digestion in the human stomach and intestines. Archives of Internal Medicine, 37(1), 110-117.

Berti, C., Riso, P., Monti, L. D., \& Porrini, M. (2004). In vitro starch digestibility and in vivo glucose response of gluten-free foods and their gluten counterparts. European Journal of Nutrition, 43(4), 198-204.

Bohn, T., Carriere, F., Day, L., Deglaire, A., Egger, L., Freitas, D., Golding, M., Le Feunteun, S., Macierzanka, A., Menard, O., Miralles, B., Moscovici, A., Portmann, R., Recio, I., Rémond, D., Santé-Lhoutelier, V., Wooster, T. J., Lesmes, U., Mackie, A. R., \& Dupont, D. (2017). Correlation between in vitro and 
in vivo data on food digestion. What can we predict with static in vitro digestion models? Critical Reviews in Food Science and Nutrition(just-accepted), 00-00.

Bornhorst, G. M., \& Singh, R. P. (2012). Bolus formation and disintegration during digestion of food carbohydrates. Comprehensive Reviews in Food Science and Food Safety, 11(2), 101-118.

Carrière, F., Renou, C., Ville, E., Grandval, P., \& Laugier, R. (2001). Advantage of expressing the variations in some digestive parameters as a function of gastric emptying instead of time. Digestion, 64(1), 46-53.

Cunin, C., Handschin, S., Walther, P., \& Escher, F. (1995). Structural changes of starch during cooking of durum wheat pasta. LWT-Food Science and Technology, 28(3), 323-328.

des Gachons, C. P., \& Breslin, P. A. (2016). Salivary Amylase: Digestion and Metabolic Syndrome. Current diabetes reports, 16(10), 102.

Dressman, J. B., Berardi, R. R., Dermentzoglou, L. C., Russell, T. L., Schmaltz, S. P., Barnett, J. L., \& Jarvenpaa, K. M. (1990). Upper gastrointestinal (GI) pH in young, healthy men and women. Pharmaceutical research, 7(7), 756-761.

French Agency for Food Environmental and Occupational Health \& Safety (2017). French food composition table . Retrieved 27/07/2018 from https://ciqual.anses.fr/In).

Fardet, A., Hoebler, C., Baldwin, P. M., Bouchet, B., Gallant, D. J., \& Barry, J.-L. (1998). Involvement of the protein network in the in vitro degradation of starch from spaghetti and lasagne: a microscopic and enzymic study. Journal of Cereal Science, 27(2), 133-145.

Fernández, C. I., \& Wiley, A. S. (2017). Rethinking the starch digestion hypothesis for AMY1 copy number variation in humans. American journal of physical anthropology, 163(4), 645-657.

Freitas, D., Le Feunteun, S., Panouillé, M., \& Souchon, I. (2018). The important role of salivary $\alpha$-amylase in the gastric digestion of wheat bread starch. Food \& Function, 200-208. 
Fried, M., Abramson, S., \& Meyer, J. H. (1987). Passage of salivary amylase through the stomach in humans. Digestive diseases and sciences, 32(10), 1097-1103.

Gardner, J. D., Ciociola, A. A., \& Robinson, M. (2002). Measurement of meal-stimulated gastric acid secretion by in vivo gastric autotitration. Journal of Applied Physiology, 92(2), 427-434.

Goñi, I., Garcia-Alonso, A., \& Saura-Calixto, F. (1997). A starch hydrolysis procedure to estimate glycemic index. Nutrition Research, 17(3), 427-437.

Goñi, I., Garcia-Diz, L., Mañas, E., \& Saura-Calixto, F. (1996). Analysis of resistant starch: a method for foods and food products. Food chemistry, 56(4), 445-449.

Granfeldt, Y., Hagander, B., \& Björck, I. (1995). Metabolic responses to starch in oat and wheat products. On the importance of food structure, incomplete gelatinization or presence of viscous dietary fibre. European Journal of Clinical Nutrition, 49(3), 189-199.

Gray, J. A., \& Bemiller, J. N. (2003). Bread staling: molecular basis and control. Comprehensive Reviews in Food Science and Food Safety, 2(1), 1-21.

Gropper, S. S., \& Smith, J. L. (2013). Digestion of Polysaccharides. In Advanced nutrition and human metabolism 6th ed., (pp. 70). United States of America: Cengage Learning.

Hoebler, C., Devaux, M.-F., Karinthi, A., Belleville, C., \& Barry, J.-L. (2000). Particle size of solid food after human mastication and in vitro simulation of oral breakdown. International Journal of Food Sciences and Nutrition, 51, 353-366.

Hoebler, C., Karinthi, A., Devaux, M.-F., Guillon, F., Gallant, D. J. G., Bouchet, B., Melegari, C., \& Barry, J.-L. (1998). Physical and chemical transformations of cereal food during oral digestion in human subjects. British Journal of Nutrition, 80(5), 429-436.

Jenkins, D., Ghafari, H., Wolever, T., Taylor, R., Jenkins, A., Barker, H., Fielden, H, \& Bowling, A. (1982). Relationship between rate of digestion of foods and post-prandial glycaemia. Diabetologia, 22(6), 450-455. 
Jenkins, D., Thorne, M., Wolever, T., Jenkins, A., Rao, A., \& Thompson, L. (1987). The effect of starchprotein interaction in wheat on the glycemic response and rate of in vitro digestion. The American journal of clinical nutrition, 45(5), 946-951.

Johnston, C. S., Snyder, D., \& Smith, C. (2017). Commercially available gluten-free pastas elevate postprandial glycemia in comparison to conventional wheat pasta in healthy adults: a double-blind randomized crossover trial. Food \& Function, 8(9), 3139-3144.

Jourdren, S., Panouillé, M., Saint-Eve, A., Déléris, I., Forest, D., Lejeune, P., \& Souchon, I. (2016). Breakdown pathways during oral processing of different breads: impact of crumb and crust structures. Food \& Function, $7(3), 1446-1457$.

Kondjoyan, A., Daudin, J.-D., \& Santé-Lhoutellier, V. (2015). Modelling of pepsin digestibility of myofibrillar proteins and of variations due to heating. Food chemistry, 172, 265-271.

Malagelada, J.-R., Go, V. L. W., \& Summerskill, W. H. J. (1979). Different gastric, pancreatic, and biliary responses to solid-liquid or homogenized meals. Digestive diseases and sciences, 24(2), 101-110.

Mathieu, V., Monnet, A.-F., Jourdren, S., Panouillé, M., Chappard, C., \& Souchon, I. (2016). Kinetics of bread crumb hydration as related to porous microstructure. Food \& Function, 7(8), 3577-3589.

Ménard, O., Cattenoz, T., Guillemin, H., Souchon, I., Deglaire, A., Dupont, D., \& Picque, D. (2014). Validation of a new in vitro dynamic system to simulate infant digestion. Food chemistry, 145, 1039-1045.

Minekus, M., Alminger, M., Alvito, P., Ballance, S., Bohn, T., Bourlieu, C., Carriere, F., Boutrou, R., Corredig, M., Dupont, D., \& Dufour, C. (2014). A standardised static in vitro digestion method suitable for food-an international consensus. Food \& Function, 5(6), 1113-1124.

Mishra, S., Hardacre, A., \& Monro, J. (2012). Food Structure and Carbohydrate Digestibility. In Carbohydrates - Comprehensive Studies on Glycobiology and Glycotechnology): InTech.

Packer, S. C., Dornhorst, A., \& Frost, G. S. (2000). The glycaemic index of a range of gluten-free foods. Diabetic medicine, 17(9), 657-660. 
Pellegrini, N., \& Agostoni, C. (2015). Nutritional aspects of gluten-free products. Journal of the Science of Food and Agriculture, 95(12), 2380-2385.

Perry, G. H., Dominy, N. J., Claw, K. G., Lee, A. S., Fiegler, H., Redon, R., Werner, J., Villanea, F. A., Mountain, J. L., Misra, R., \& Carter, N. P. (2007). Diet and the evolution of human amylase gene copy number variation. Nature genetics, 39(10), 1256.

Pletschke, B. I., Naudé, R. J., \& Oelofsen, W. (1995). Ostrich pepsins I and II: a kinetic and thermodynamic investigation. The international journal of biochemistry \& cell biology, 27(12), 1293-1302.

Read, N. W., Welch, I. M. L., Austen, C. J., Barnish, C., Bartlett, C. E., Baxter, A. J., Brown, G., Comption, M. E., Hume, K. E., \& Storie, I. (1986). Swallowing food without chewing; a simple way to reduce postprandial glycaemia. British Journal of Nutrition, 55(1), 43-47.

Skude, G., \& Ihse, I. (1976). Salivary amylase in duodenal aspirates. Scandinavian journal of gastroenterology, 11(1), 17-20.

Squires, B. T. (1953). Human salivary amylase secretion in relation to diet. The Journal of physiology, 119(23), 153-156.

Stylianopoulos, C. L. (2012). Carbohydrates: Requirements and Dietary Importance. In B. Caballero, L. H. Allen \& A. Prentice (Eds.), Encyclopedia of human nutrition 2nd ed., (pp. 316-321): Academic press. Woolnough, J. W., Bird, A. R., Monro, J. A., \& Brennan, C. S. (2010). The effect of a brief salivary $\alpha$-amylase exposure during chewing on subsequent in vitro starch digestion curve profiles. International journal of molecular sciences, 11(8), 2780-2790. 


\section{Table}

Table 1: Composition of the studied foods. All values were experimentaly obtained except for the protein content of bread which was estimated from the French food composition table (French Agency for Food Environmental and Occupational Health \& Safety, 2017).

\begin{tabular}{l|c|c|c}
\hline & Bread & $\begin{array}{c}\text { Wheat } \\
\text { spaghetti }\end{array}$ & $\begin{array}{c}\text { Gluten-free } \\
\text { spaghetti }\end{array}$ \\
\hline $\begin{array}{l}\text { Water } \\
\text { (g/100 g of food) }\end{array}$ & $45.7 \pm 0.4$ & $65.4 \pm 0.1$ & $68.8 \pm 8.8$ \\
\hline $\begin{array}{l}\text { Protein } \\
\text { (g/100 g of food) }\end{array}$ & 7.4 & 5.0 & 2.4 \\
\hline $\begin{array}{l}\text { Total starch } \\
\text { (g/100 g of food) }\end{array}$ & $47.2 \pm 1.1$ & $27.4 \pm 1.3$ & $27.9 \pm 0.2$ \\
$\begin{array}{l}\text { Digestible starch } \\
\text { (g/100 g of total starch) }\end{array}$ & $96.6 \pm 0.6$ & $86.6 \pm 1.1$ & $95.6 \pm 0.7$ \\
$\begin{array}{l}\text { Resistant starch } \\
\text { (g/100 g of total starch) }\end{array}$ & $3.4 \pm 0.6$ & $13.4 \pm 1.1$ & $4.4 \pm 0.7$ \\
\hline
\end{tabular}


Figures

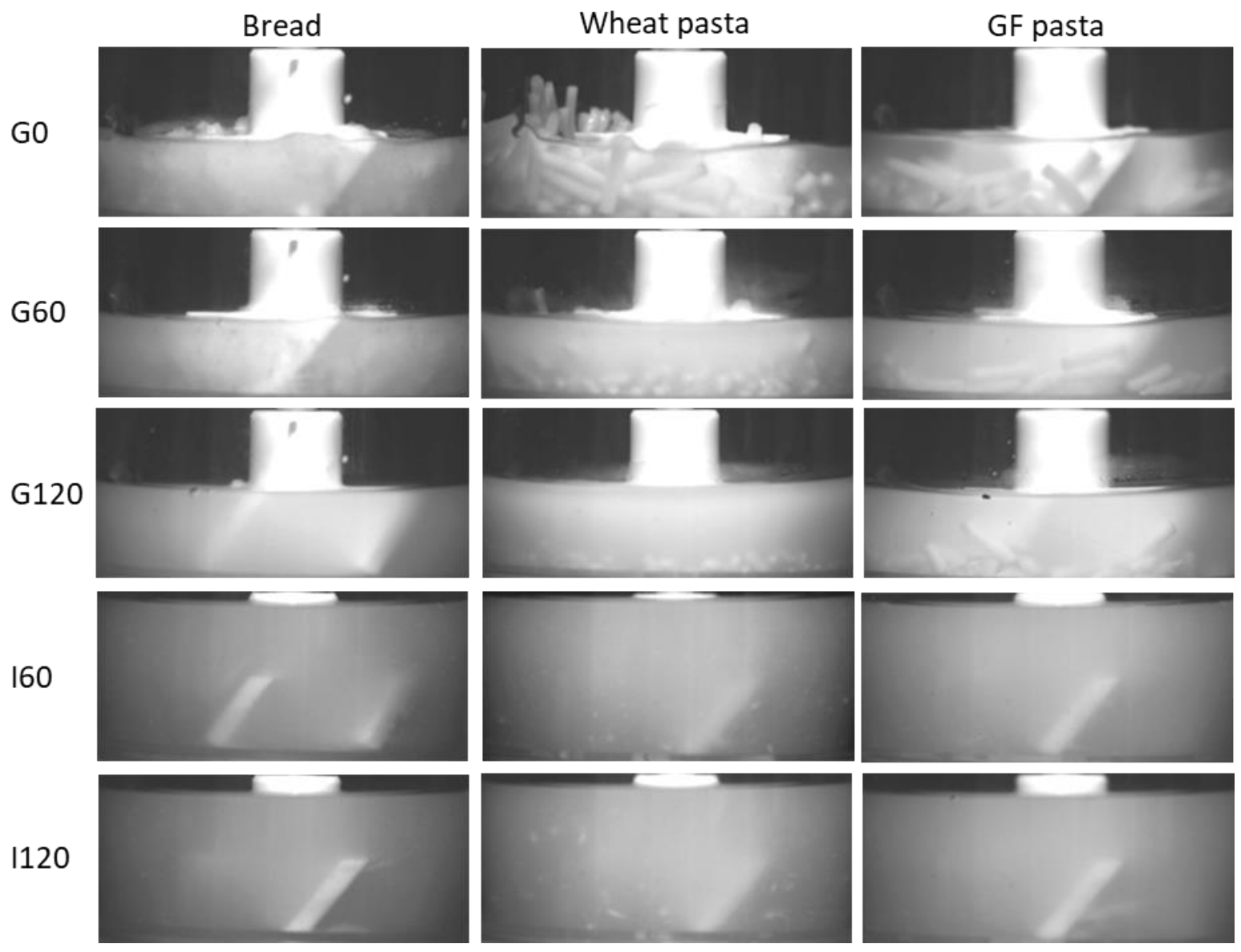

Figure 1 - Devolution of food macrostructure. Pictures taken at the end of the oral phase/start of the gastric phase (G0), and 60 and 120 min of after the start of both the gastric (G) and intestinal (I) phases of digestion ( $t=0,60,120,180$ and $240 \mathrm{~min})$. 

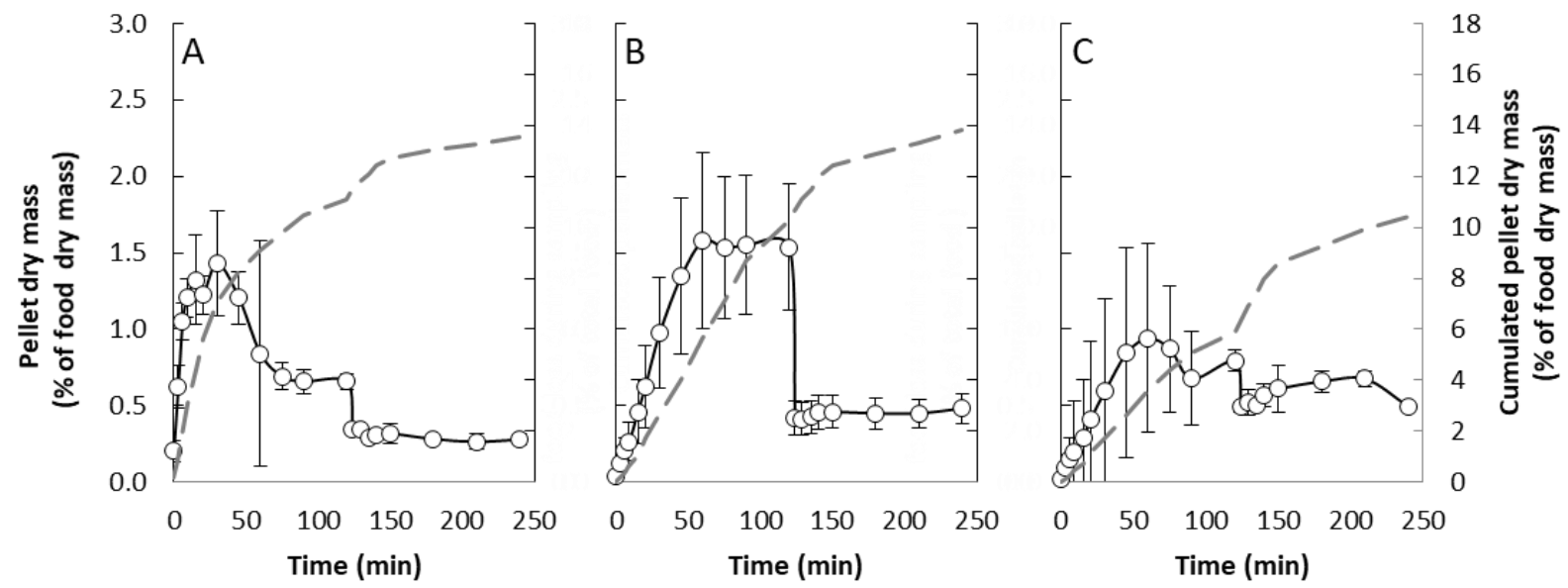

Figure 2 - Dry masses of fine particle pellets. Incremental (-O-, left hand y-axis) and cumulative (- - -, right hand $y$-axis) dry mass of the fine particle pellet of centrifuged samples, expressed as percentage of the initial dry mass of food, during the course of oro-gastro-intestinal digestions in vitro: (A) Bread, (B) Wheat spaghetti and (C) Gluten-free spaghetti. Average \pm SD, 3 rpt.
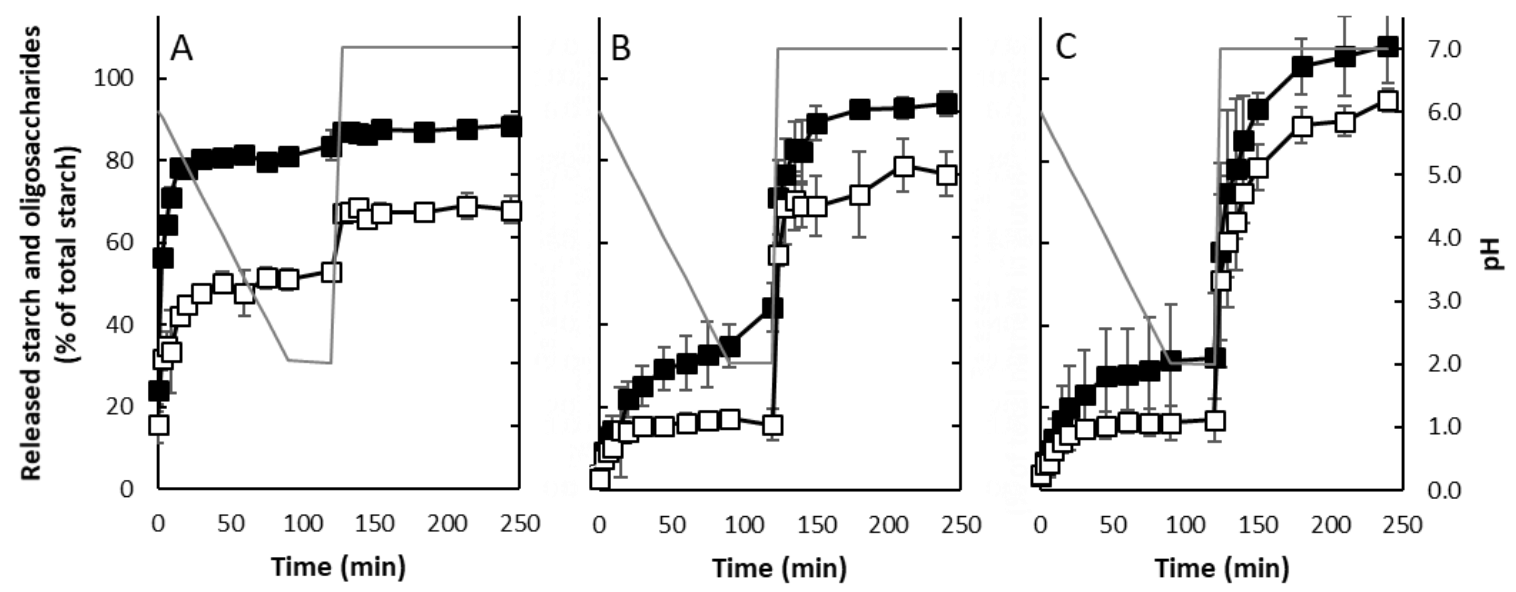

Figure 3 - Starch digestion. Released starch (-口-), oligosaccharides (- $\square-$ ), and pH of the chime (-) during the course of in vitro oro-gastro-intestinal digestions: (A) Bread, (B) Wheat spaghetti, (C) Gluten-free spaghetti. Average \pm SD, 3 rpt. 


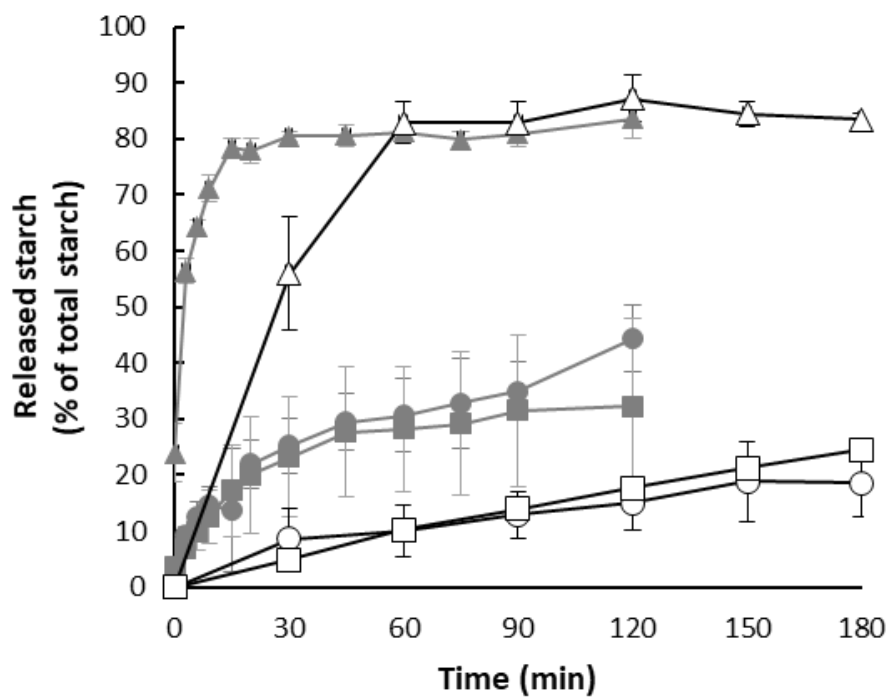

Figure 4 - Comparison of digestion protocols. Kinetics of starch obtained during our gastric digestions (grey symbols), and with the protocol of Goñi et al. (1997) commonly used to predict the Gl of foods (white symbols). Starch release during digestion of white wheat bread (- $\Delta$ - and $-\Delta-$ ), wheat spaghetti (- $\square$ - and $-\square-)$ and gluten free spaghetti (-०- and -○-). 